\title{
長管骨骨幹部骨折における骨折治癒過程 一多施設共同研究一
}

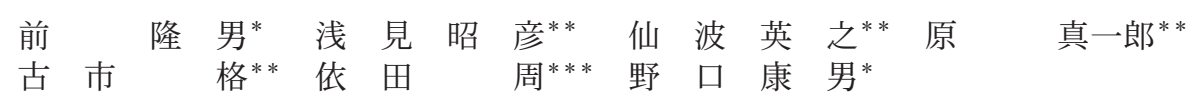

\section{Process of Fracture-Healing in Diaphysis of Tubular Bones -A Multicenter Study-}

Takao Mae*, Akihiko Asami**, Hideyuki Semba**, Shinichiro Hara**, Itaru Furuichi**, Itaru Yoda***, and Yasuo Noguchi*

【目的】骨折治癒は骨折型，部位や手術方法などによりその期間が異なる，四肢長管骨骨幹部骨折にお いて仮骨形成過程について検討する【方法】佐賀骨折治療研究会に属する 5 病院で術後の仮骨出現, 仮骨 形成時期を調查した。仮骨出現, 仮骨形成の判定には当会の仮骨形成基準を採用した。【対象】上腕骨, 橈骨，尺骨，大腿骨，脛骨の骨幹部骨折で 2007 年 8 月から 2009 年 7 月までで術後半年以上追跡可能な 152 例を対象とした。【調査項目】仮骨形成期間，骨折型，手術術式，性別，年齢，骨折部位とした。 【結果】仮骨出現時期と形成時期では年齢，固定法，骨折部位によって差を認めた。【考察】骨折治癒過 程である仮骨出現から形成までの期間を全体的に検証した結果，骨折部位，固定法，年齢，骨折型の相違 が仮骨形成過程に影響を及ぼしていることが示唆された．部位別に検討してもその治療方法，骨折型など によって治瘜過程が異なる可能性がある.

This study was conducted to investigate the healing of tubular bone fracture. We studied the process of callus formation in 152 fractures collected from five facilities belonging to the SAGA Society for Fracture Repair.

Callus formation was monitored by radiological assessment defined by our original criteria. As a result, we recognized a statistical significant difference in several factors such as, fracture site, implant, age, and classification. We are planning to compile a database on this research as an index for fracture treatment.

Key words : callus (仮骨), diaphyseal fracture (骨幹部骨折), multicenter study (多施設共同研究)

$$
\text { はじめに }
$$

日常診療において骨折部位, 固定方法, 骨折型によつ てその治瘾期間が異なることをしばしば経験する。し かしながら，現在まで骨折治癒期間特に仮骨形成に関 した研究は国内外ともほとんど見当たらない。骨折治 療をする上で重要な仮骨形成期間とそれに影響を与え
る要因を明らかすることが重要である，今回我々は佐 賀県における多施設共同研究を行い, 長管骨骨幹部骨 折のおける仮骨形成過程を調查しその要因を検討した.

対象

佐賀骨折治療研究会に属する 5 病院（表 1）におい て 2007 年 8 月から 2009 年 7 月までに手術を施行され

\footnotetext{
* 佐賀県立病院好生館整形外科 Department of Orthopaedic Surgery, Saga Prefectural Hospital KOSEIKAN, Saga, Japan

** 佐賀骨折治療研究会 Department of Orthopaedics, National Hospital Organization Ureshino Medical Center, Saga, Japan

*** 長崎原爆病院整形外科 Department of Orthopaedics, the Japanese Red Cross Nagasaki Genbaku Hospital, Nagasaki, Japan
} 
表 1 佐賀骨折治療研究会所属病院

佐賀県立病院好生館

唐津赤十字病院

佐賀社会保険病院

国立病院機構嬉野医療センター

国立病院機構佐賀病院

\section{骨折型}

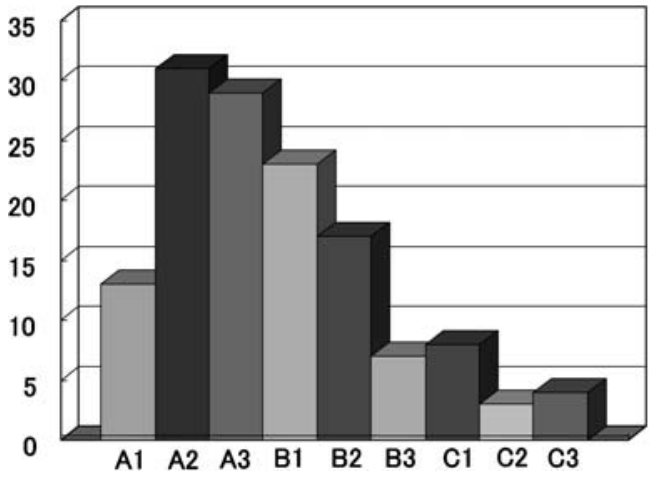

図 $1 \mathrm{AO}$ type $\mathrm{A} 2, \mathrm{~A} 3, \mathrm{~B} 1$ が $60 \%$ を占めている

た上腕骨，橈骨，尺骨，大腿骨，脛骨骨幹部骨折のう ち, 術後半年以上追跡可能な 152 例を対象とした.内 訳は男性 74 例，女性 78 例であった。

年齢は 8 歳から 97 歳で平均 54.2 歳であった。骨折 部位別には尺骨 7 例，橈骨 11 例，前腕 20 例，上腕骨 8 例，大腿骨 57 例，脛骨 42 例であった．骨折型では AO Type A2，A3，B1 が $60 \%$ を占めた（図 1)。ま た固定方法はネイル $50 \%$ ，プレートが $30 \%$ 使用され た (図 2).

$$
\text { 方法 }
$$

術後の経時的単純レントゲンで骨折部の仮骨出現, 仮骨形成を調査した，仮骨出現，形成に関しては佐賀 骨折治療研究会および依田による仮骨形成基準を用い た ${ }^{3}$. これらの仮骨形成過程において骨折型，手術術 式，性別，年齢，骨折部位との関連性を検討した.

$$
\text { 結果 }
$$

骨折部位別に仮骨形成過程を検討した結果，大腿骨 $5.40 \pm 0.82$ (Ave. \pm 2 S.E.)（週），脛骨 $5.35 \pm 0.93$ (週)，
固定方法

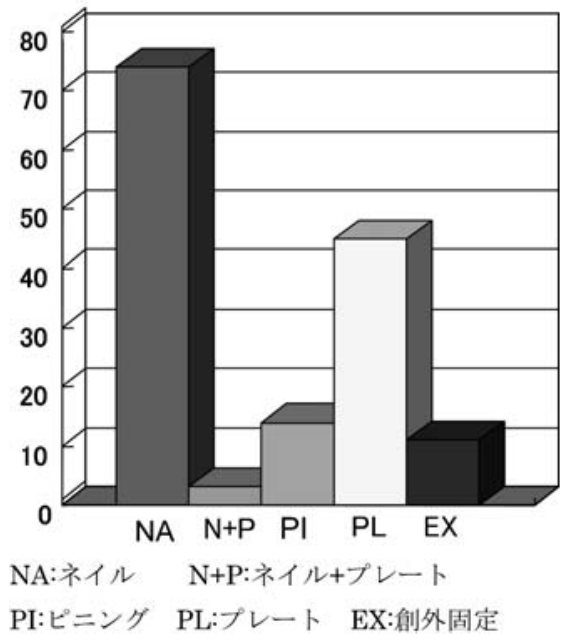

図 2 ネイルが $50 \%$ ，プレートが $30 \%$ に使用された

上腕骨 $4.2 \pm 0.98$ (週)，前腕 $3.8 \pm 0.93$ (週)，橈骨 1.4 \pm 0.82 （週），尺骨 $1.0 \pm 0.75$ （週）となり，全体をみ ると統計学的に有意な差が確認された（図 3). 固定 方法の検討では仮骨出現時期，形成時期に差を認めた. 骨折型においては AO Type A 8.76 001.16 (週)， Type B $11.78 \pm 1.84$ (週)，Type C 8.71 \pm 1.89 (週) となり仮骨出現，仮骨形成とも差が認められた。一方， 年齢との相関を検討すると仮骨出現で相関係数 0.25 $(\mathrm{P}=0.0014)$ ，仮骨形成で相関係数 $0.37(\mathrm{P}=<.001)$ ， 仮骨形成一出現（仮骨成熟）で相関係数 $0.21(\mathrm{P}=$ 0.0104）とそれぞれ弱い相関を認めた。性差と仮骨形 成過程を検討した結果，有意な差はなかった（表 2).

考察

長管骨骨折における仮骨形成過程を検討した文献は 国内外とも見当たらない．わずか低出力超音波パルス 治療の研究の対照群として仮骨形成を示したものがあ るのみである。

Kwok-Sui 等2) は研究の中で粉砕脛骨骨折の第一仮 骨形成を $9.5 \pm 2.2$ （週）と報告している. Heckman 等1) は脛骨骨折の仮骨形成を $92 \pm 10.0$ (日）としてい る. 本研究の脛骨仮骨形成時期は $11.13 \pm 1.60$ (週) でこれらの報告と比較して妥当な結果と考えられる. 部位別では大腿骨，脛骨を比較すると似通った仮骨 
仮骨出現（週）

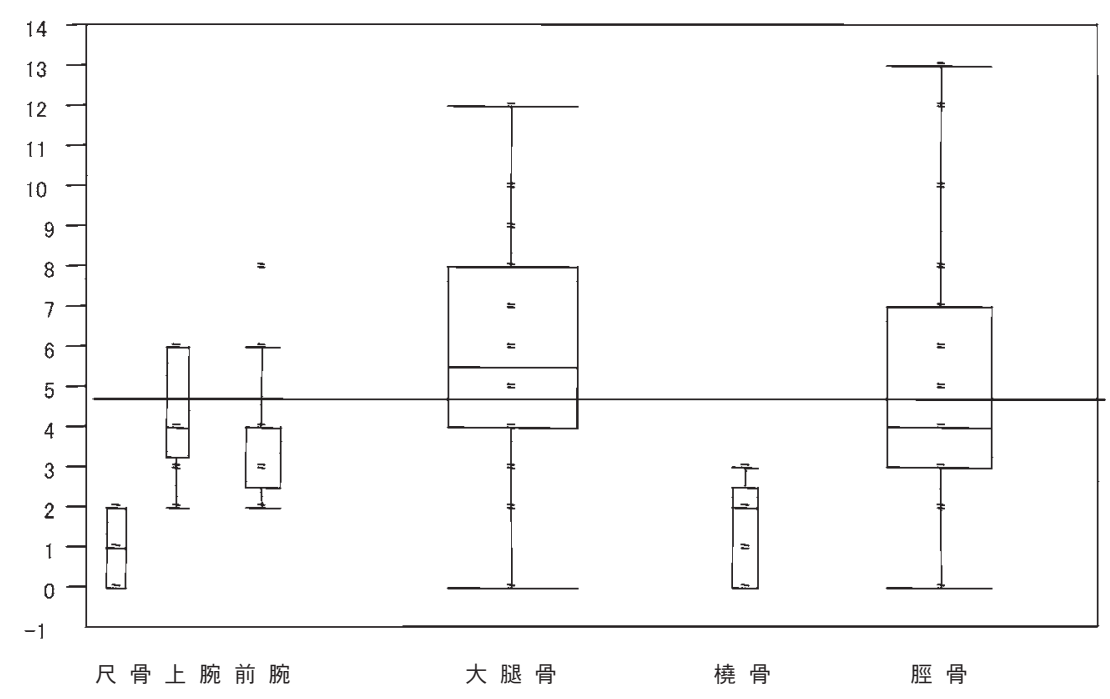

仮骨形成（週）

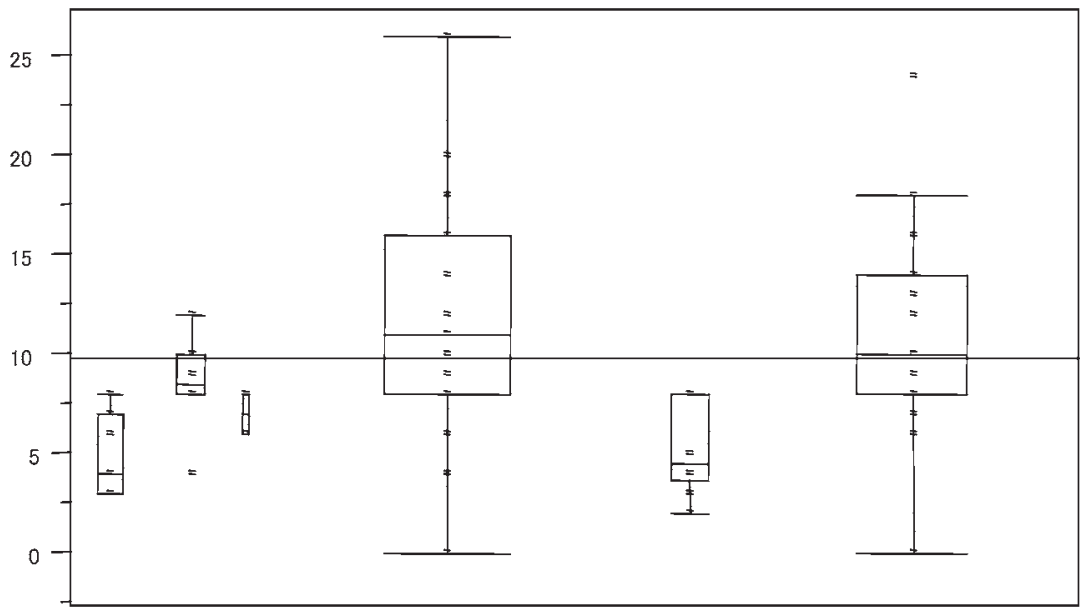

尺骨上腕前腕大腿骨橈骨骨

図 3 骨折部位での検討で仮骨形成過程において統計学的に有意な差を認めた.

表 2 要因別の仮骨形成過程の検討

\begin{tabular}{l|l|l|l|l}
\hline \hline & \multicolumn{1}{|c|}{ 仮骨出現 } & 仮骨出現 形成 & \multicolumn{1}{|c}{ 仮骨形成 } & \multicolumn{1}{c}{ 備考 } \\
\hline 骨折部位 & $\mathrm{p}=<0.0001$ & n.s. & $\mathrm{p}=<0.0001$ & 一元配置分散分析 \\
骨折型 & n.s. & $\mathrm{p}=0.0174$ & $\mathrm{p}=0.0116$ & 一元配置分散分析 \\
固定方法 & $\mathrm{p}=0.0002$ & n.s. & $\mathrm{p}=0.0007$ & 一元配置分散分析 \\
年齢 & $0.25(\mathrm{p}=0.0014)$ & $0.21(\mathrm{p}=0.0104)$ & $0.37(\mathrm{p}=<.0001)$ & 相関係数検定 \\
性別 & n.s. & n.s. & n.s. & t 検定 \\
\hline
\end{tabular}


表 3 大腿骨のおける固定方法の検討

\begin{tabular}{c|c|c|c|c}
\hline \hline 大腿骨 & 数 & 仮骨出現 & 仮骨出現〜形成 & 仮骨形成 \\
\hline ネイル & 35 & $5.71 \pm 0.97$ & $5.28 \pm 1.43$ & $11.08 \pm 1.99$ \\
プレート & 8 & $5.00 \pm 2.00$ & $10.80 \pm 8.15$ & $15.20 \pm 7.40$ \\
& & n.s. & $\mathrm{p}=0.075$ & n.s. \\
\hline
\end{tabular}

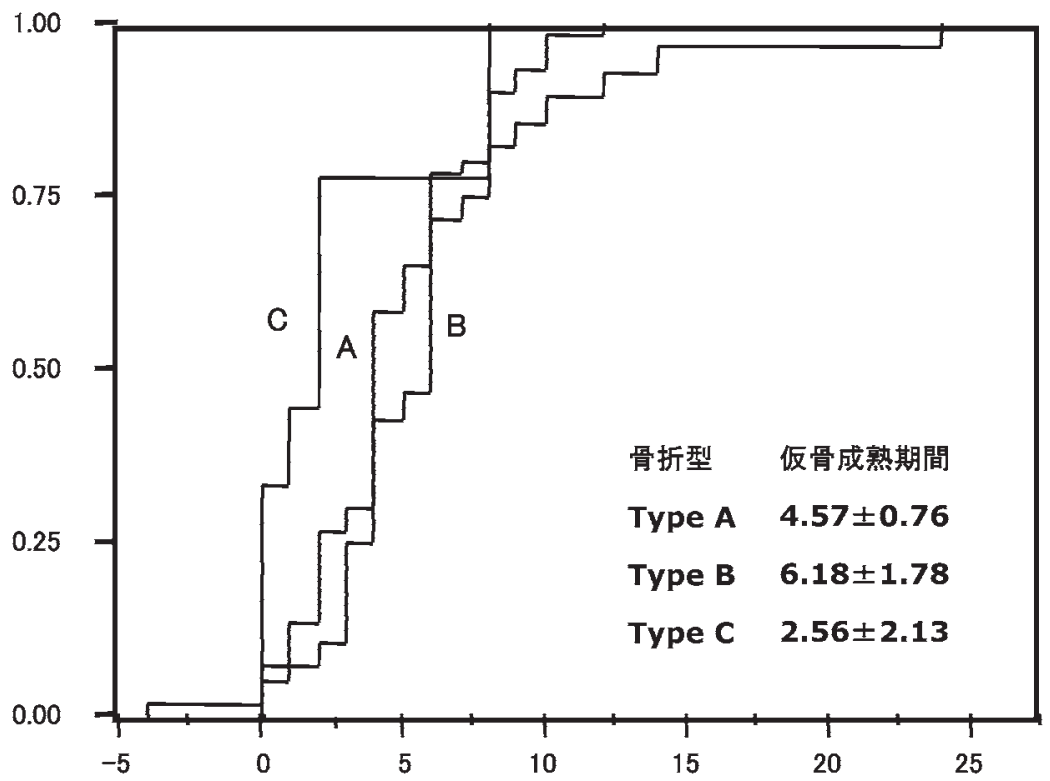

図 4 Type C の粉砕骨折では仮骨出現は遅れがちであるが, いったん出 現すると有意に早く架橋した.

形成時期を示しており，これは今まで経験的に納得で きる結果となつた，有意な差が出ている橈骨，尺骨は 小児骨折が含まれている為, この影響が強いと思われ る. 固定方法に関しては症例数の多いネイルとプレー トの双方を比較検討した結果，大腿骨，脛骨とも有意 差はなかったが，大腿骨においてはネイルでの仮骨出 現から仮骨形成までの期間が短縮されている傾向が認 められた（表3).

一方, 骨折型による仮骨形成過程の検討において Type B の仮骨形成が遅れている傾向が認められた。 Type A で本症例では斜骨折，らせん骨折がおおく骨 癒合に有利な骨折形態であった事が影響を及ぼしてい るものと考えられる。 Type C における要因として粉 砕骨折の割合が多いため外力に対する応力分散が可能 となり仮骨形成に有利に作用しているものと推測でき
る。これを仮骨形成過程の累積確率を見ると, Type $\mathrm{C}$ では仮骨出現は早くないものの一端出現すると有意 に架橋して仮骨形成に到達することが見て取れる（図 4).

Type B では Bending forceによる骨折であること が多く, 骨膜軟部組織の破綻が合併し，仮骨形成遅延 傾向となっているのであろう.

$$
\text { ま と め }
$$

今回我々は長管骨骨幹部骨折における仮骨形成過程 を調査した。

大腿骨，脛骨における仮骨出現は $5 \sim 6$ 週程度必要 であり, 仮骨形成は $10 \sim 13$ 週という結果が得られた. これらは今までの報告と比較して妥当な結果と判断さ れる. 
また，仮骨出現，仮骨形成時期において骨折型，骨 折部位による統計学的に有意な差を認めた。年齢には 相関がみられたが，固定方法には有意な差が確認され なかった。

今後は骨折部位毎の固定法, 骨折型の解析が重要で あり，これらは今後の骨折治療の指針となる可能性が 示唆された.

\section{参 考 文 献}

1) Heckman, J. D., et al.: Acceleration of tibial fracture-healing by non-invasive, low-intensity pulsed ultrasound. J. Bone Joint Surg. Am., 76(1) : 26-34, 1994.

2) Leung, K.S., et al.: Complex tibial fracture outcomes following treatment with low-intensity pulsed ultrasound. Ultrasound Med. Biol., 30 (3) : 389-395, 2004.

3）依田 周ほか：骨癒合評価時期に対する検討一メール アンケートを用いてー。整外と災外，59(3)：613-618, 2010. 